$1-1-2008$

\title{
Evaluating the Applicability of Socially-Oriented Perspectives to the IT Service Level Agreement Negotiation Process: A Theory-Driven Exploratory Study
}

Daniel S. Soper

Haluk Demirkan

University of Washington Tacoma, haluk@uw.edu

Michael Goul

Follow this and additional works at: https://digitalcommons.tacoma.uw.edu/business_pub

\section{Recommended Citation}

Soper, Daniel S.; Demirkan, Haluk; and Goul, Michael, "Evaluating the Applicability of Socially-Oriented Perspectives to the IT Service Level Agreement Negotiation Process: A Theory-Driven Exploratory Study" (2008). Business Publications. 62.

https://digitalcommons.tacoma.uw.edu/business_pub/62 


\title{
Evaluating the Applicability of Socially-Oriented Perspectives to the IT Service Level Agreement Negotiation Process: A Theory- Driven Exploratory Study
}

\section{Daniel S. Soper*}

Doctoral Program in Information Systems

W. P. Carey School of Business, Arizona State University

Tempe, AZ 85287, USA

E-mail: Daniel.Soper@asu.edu

\section{Haluk Demirkan}

Assistant Professor in Information Systems

W. P. Carey School of Business, Arizona State University

Tempe, AZ 85287, USA

E-mail: Haluk.Demirkan@asu.edu

\section{Michael Goul}

Professor in Information Systems

W. P. Carey School of Business, Arizona State University

Tempe, AZ 85287, USA

E-mail: Michael.Goul@asu.edu

* Corresponding author

\begin{abstract}
Continuing exponential growth in the IT outsourcing market implies a need to understand the negotiated service level agreements (SLAs) that underlie the majority of those sourcing relationships. Knowledge of the negotiation processes that are associated with the development of IT SLAs is a necessary precondition for designing and developing Negotiation Support Systems (NSSs) intended to support those processes. To gain such knowledge, it is first necessary to identify theoretical perspectives that may be relevant to the IT SLA negotiation process, postulate reasonable propositions there from, and then evaluate those propositions in a practical, exploratory fashion. Accordingly, the current paper draws on socially-oriented perspectives to develop theory-driven propositions which are then evaluated in an experimental setting. The results of the study indicate that several socially-oriented theories may be relevant to the IT service level agreement negotiation process, and represent a starting point for the identification of context-specific IT SLA negotiation support systems.
\end{abstract}

Keywords: IT services, services science, service level agreements, negotiation support systems, negotiation

Reference to this paper should be as: Soper, D., Demirkan, H. and M. Goul (2008) 'Evaluating the Applicability of Socially-Oriented Perspectives to the IT Service Level Agreement Negotiation Process: A Theory-Driven Exploratory Study', Intl.. J. Serv. Sci., Vol. x, No. x, pp. $\mathrm{xx}-\mathrm{xx}$.

Biographical notes: Dan Soper is a Ph.D. candidate in the Department of Information Systems in the W. P. Carey School of Business at Arizona State University. He recently received the Best Paper award in the Data Warehouse and Business Intelligence track of the 38th International conference on System Sciences. Dan is a fourth year student in the Ph.D. program at ASU, and his research interests include IT service level agreement negotiation.

Soper, D. S., Demirkan, H., \& Goul, M. (2008). Evaluating the applicability of socially-oriented perspectives to the IT service level agreement negotiation process: a theory-driven exploratory study. International Journal of Services Sciences, 1(3-4), 267-287.Copyright (C) 2008 Inderscience Enterprises Ltd. 
Haluk Demirkan is an Assistant Professor of Information Systems in the W. P. Carey School of Business at Arizona State University. Haluk's main research interests and expertise are in services-centric computing and the management of outsourcing relationships. Haluk has published or is forthcoming, and presented his research in a number of academic/ industry journals and conferences; such as Information Systems and e-Business Management, Information Systems Frontiers, the Communications of the ACM, IEEE Transactions, European Journal of Operations Research, AMCIS, HICSS, and DSI. He has authored or co-authored over twenty articles in refereed journals and proceedings, and he has served as a special issue editor, mini-track co-chair and program chair. Haluk holds a PhD in Decision \& Information Sciences; M.E. in Industrial \& Systems Eng. from the University of Florida, and B.S. in Mechanical Eng. from Istanbul Technical University.

Michael Goul is a Professor of Information Systems. His research has been published in a wide range of both academic and practitioner journals, and his recent research interests are in the area of e-Government. He has published in journals including Decision Support Systems, Journal of Management Information Systems, Decision Sciences, Information \& Management, IEEE Expert, Data Base, Communications of the ACM and other journals. He has served as journal editor, special issue editor, AIS Vice President, Conference and Program Chair, and he is now the Chair of the AIS special interest group in decision support, knowledge and data management systems.

\section{INTRODUCTION}

As globalization continues to effect substantial improvements in international connectivity and electronic communication, outsourcing has emerged as one of the leading global trends in information technology (IT) management. In an effort to focus on core competencies, many organizations have altered their IT acquisition and support strategies and are now obtaining IT services and products from internal and external business partners through formallydetailed contractual agreements. According to recent estimates, global IT outsourcing expenditures reached USD $\$ 176.8$ billion in 2003, and are expected to exceed USD\$235.6 billion in 2007 (Gartner, 2004). Although global IT outsourcing expenditures are continuing to grow at an exponential rate, emerging evidence suggests that many of the formal contracts that undergirder IT outsourcing agreements are being written in a very ineffective way. Rather than focusing on the customization of the critical business and technical service levels that are necessary to support the attainment of an organization's business process objectives and IT needs, the content of many IT outsourcing contracts is instead characterized by buffers and safeguards that protect IT service providers from nonperformance conditions (Braunstein, 2004). To address this problem, many firms are beginning to abandon these broad, generic service contracts in favor of detailed service level agreements (SLAs) that more fully subsume the customized IT product and service needs of the organization. As Karten defined them, SLAs are "formally negotiated agreements that help to identify expectations, clarify roles and responsibilities, and facilitate communication between a service provider and its customer" (Karten, 1998).The goal of such service level agreements is not only to guarantee the quality of the services provided to the requesting organization, but also to provide for the ongoing management of the formal outsourcing relationship that exists between the business partners. Both parties in the IT SLA negotiation process generally desire an agreement that will yield long-term mutual benefits, and to that end most IT SLAs either formally define a longterm relationship or include specific provisions for renegotiating the next version of the agreement. It is therefore in the best interest of both parties to make an IT SLA work by contractually achieving some level of equilibrium between the needs of the customer and the provider's ability to perform for the negotiated cost. To accomplish these goals, IT SLAs explicitly address the expectations of each party by detailing service levels and costs, and by specifying penalties and remedies for failure to perform at the negotiated levels. In order to determine the current issues and needs surrounding the management of the IT outsourcing process, a study involving 182 mid-level and executive managers was recently undertaken by a major business service management organization (NextSLM, 2000). The results of this study indicate that the most pivotal factor contributing to the success of IT outsourcing initiatives is the presence of a well-written, negotiated service level agreement that effectively addresses the roles and responsibilities of the business partners, including specific goals and objectives, reporting policies, help desk availabilities, penalties, incentives, and adjustment procedures -- all with specific clauses that contain quantifiable performance metrics.

Despite the presence of an extensive body of research on negotiation, an important gap remains with respect to the preparation of well-written IT outsourcing SLAs that are constructed through formal negotiation processes. Research has, however, been conducted in the area of requirements analysis involving multi-stakeholder negotiation scenarios, and by relying upon what is known as "Theory W", these research efforts have endeavored to incorporate theoretical findings into negotiation support systems that embody the Win-Win Spiral Model (Boehm and In, 1996; Egyed and Boehm, 1999). The intent of this research stream has been to develop normative approaches 
for improving requirements analysis across multiple projects, a goal that is clearly reflective of the repeatability objective forwarded by the Software Engineering Institute's Capability Maturity Model (Humphrey, 1989; SEI, 1995). At its core, Theory $W$ embodies the principle that projects are successful when all of the parties involved are winners.

While much has been learned by examining multistakeholder negotiation processes, the rapid expansion of IT outsourcing relationships -- coupled with the increasing adoption of service level agreements as a tool for managing those relationships -- implies a pressing need for IT SLA negotiation-focused research. Such research can almost certainly build upon what has been addressed in the requirements analysis area, as the proliferation of the IT outsourcing model presumes the development of contractual agreements -- many of which are formulated by organizational representatives who negotiate with one or more vendors to develop an SLA. Negotiated SLA clauses and financial schedules are similar to requirements analysis in the sense that multiple stakeholders are involved in the process, and the potential exists for a negotiating team to neglect issues of importance to each and every class of stakeholder -- particularly where those issues are expressed in vague terms that must be interpreted and then precisely articulated as contractual elements. Regardless of whether the process is viewed from the perspective of the purchasing organization or from the perspective of the service provider, the development of high-quality IT SLAs is currently being hindered by a general lack of understanding regarding the key impediments that encumber IT SLA negotiations. Furthermore, there are few proven research methods upon which to build, excepting for those that can be adopted from the requirements analysis negotiation literature and the more general negotiation support system literature. Through an examination of relevant theoretical bases, this paper seeks to contribute to the resolution of these issues by postulating normative approaches that can be used to facilitate the negotiation of IT service level agreements.

In the next section we provide an overview of the existing theories of negotiation, emphasizing the social perspective and its relevance to the IT SLA negotiation process. After reviewing the research questions and model in section three, section four provides managerial insights abstracted from the results of an experimental study. In the last section, we discuss our conclusions and suggest avenues for future research.

\section{THEORETICAL FOUNDATIONS}

If we examine economic models of decision-making such as production, transaction, or agency cost theories, we note that they primarily focus on cost savings as the most significant aspect. Social perspectives, as an addition to economic model perspectives, can provide further insight into the facets of decision-making involved in complex and dynamic decision processes such as IT SLA negotiation. This implies that while economic models have a significant theoretical role in supporting research on IT outsourcing decision-making, the negotiation of acceptable IT outsourcing contracts may well rely on additional theoretical bases. This implication is supported in literature examining the effects of partnership quality on IT outsourcing success (Lee and Kim, 1999). As such, it can be reasonably inferred that sociological theory can serve as a significant reference framework for examining the negotiation of IT outsourcing SLAs. As both parties in the SLA negotiation process generally desire an agreement that yields long-term mutual success, most IT SLAs either formally define a long-term relationship or include specific provisions for renegotiating the next version of the agreement. It is therefore in the best interest of both parties to make an IT SLA work by contractually achieving some level of equilibrium between the needs of the customer and the provider's ability to perform for the negotiated cost.

With respect to evaluating the relevance of sociallyoriented theories to the IT SLA negotiation process, it is necessary to consider the status of the relationship between the parties involved in the negotiation. While certain theoretical perspectives may have relevance in the context of an initial IT SLA negotiation, additional theoretical perspectives may become relevant when an IT SLA is being renegotiated as a part of an ongoing interorganizational relationship. It is also necessary to differentiate between two-party and multiparty negotiations, as additional complexities -- such as the formation of coalitions -may arise in multiparty negotiation environments (Polzer, et al., 1998). A detailed theoretical understanding of the IT SLA negotiation process therefore requires that four specific negotiation scenarios be considered; these scenarios are depicted in the 2 x 2 matrix shown in Figure 1 below.

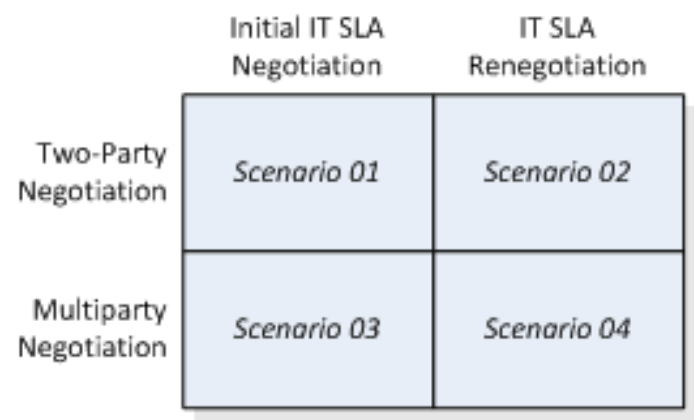

Figure 1 IT SLA Negotiation Scenarios

As research progresses from the least complex scenario (Scenario 01) to the most complex scenario (Scenario 04), an increasingly complete understanding of the IT SLA negotiation process will emerge. Accordingly, the current paper focuses primarily on Scenario 01, but also includes a brief discussion of additional theoretical perspectives 
that may have relevance for Scenario 02, thereby establishing a basis for future work in this area.

With respect to Scenario 01, models closely allied with sociological theories are typically descriptive rather than prescriptive. Such models interpret the negotiation process from a number of different perspectives including learning, individual behaviors, joint decision-making, comparison of alternatives, etc. (Lim and Benbasat, 1992-1993). Central to many of these models is social exchange theory, the core concept of which is a longitudinal exchange relationship between actors whereby there is give-and-take in the actors' relations to one another (Kern, 1997). This theory focuses on the subjective cost-benefit analyses performed by each party as they attempt to manage the relationship, and predicts that the parties will maintain the relationship until one of them believes the perceived costs to outweigh the perceived benefits. In a similar vein, the work of Homans led to the development of equity theory (Homans, 1961), which postulates that parties will strive to create and maintain conditions of justice. Under this explanatory framework, a party will resist attempts to alter the terms of the IT SLA as long as it is getting what it wants from the other party. With respect to managing this relationship, Bartos offered a theory based on the work of Homans which presumes that negotiators view the midpoint between their past demands and offers as "just," and that they strive to meet at that midpoint with an eye towards fairness as achieved through reciprocation (Bartos, 1978).

From another perspective, Cross sees negotiation as being part of a learning process (Cross, 1978). Negotiators choose bargaining strategies in an attempt to optimize their payoffs from the situation, and may alter their strategies as the negotiation progresses. Negotiating strategies are chosen based upon each party's perceptions of their opponent's strategies, which in turn are based upon the way each negotiator gathers and collects information. With respect to negotiation as a learning process, there is some evidence that IT SLA negotiation is greatly improved through learning processes used to close the knowledge gap that exists between a customer and service provider (Köppel, et al., 1999). In addition to the learning perspective, the quality of the partnership has also been identified as an important aspect impacting IT SLA negotiations (Lim and Benbasat, 1992-1993). From yet another perspective, Bereby-Meyer, et al. state that organizational teams are a fundamental learning and decision-making unit (Bereby-Meyer, et al., 2004). They find that highlearning teams (with high-learning goals, high-learning values, and team discussions) perform better than lowlearning teams (with performance goals, low-learning values, and no team discussions).

With respect to the negotiation process in particular, Ury et al. propose principled negotiation as a win-win approach to reaching a lasting agreement (Ury, et al., 1991). Under this model, the focus of the negotiation is on the interests of the parties rather than on their positions. Par- ties using principled negotiation will generate several distinct options before arriving at an agreement, and should insist that the final agreement be based solely on objective measures. Similarly, Rahwan et al. introduce an interestbased negotiation theory, wherein one party may influence their opponent's preferences by discussing the underlying motivations for adopting specific goals in a negotiation, thereby shifting the discussion away from outcomes to the relevance of those goals (Rahwan, et al., 2003). In order for this theory to be applicable in a negotiation environment, both parties need to be very knowledgeable about each other, and inter-party trust is presumed to be high.

Other aspects of human behavior, including complacency and individual differences, have also been introduced into this area (Prinzel III, et al., 2001). Such aspects are likely relevant to some stages of IT SLA negotiation, and will merit further examination if a more general social theory is shown to apply to the IT SLA negotiation process. Similarly, another potentially important consideration related to IT SLA negotiation involves individuals' prefactual and counterfactual thinking processes. Defensive pessimism and optimism have been included in a proposed model describing aspects of an individual's selfesteem when they are entering "risky" situations (Norem and Cantor, 1986). Defensive pessimism, which engages prefactual thinking, involves setting low expectations prior to entering a situation. Such negotiators acknowledge a history of success in a situation, but enter that situation "expecting the worst". An optimistic strategy, which involves counterfactual thinking, is where expectations are high at the outset. The defensive pessimist strategy seems to act as a form of natural cognitive therapy for those using it. In an exemplar study, defensive pessimists engaged in downward (worse than expected) prefactual thinking, whereas optimists preferred counterfactual thinking (Sanna, 1996). It has also been shown that both groups use their preferred strategies effectively. Performance suffers, however, when the preferred strategy is unavailable.

As noted previously, many IT SLAs include specific provisions for renegotiating the next version of the agreement. Such provisions provide an in-built mechanism for establishing and maintaining a long-term, sustainable interorganizational relationship following a successful initial SLA negotiation. The iterative renegotiation of IT SLAs over a lengthy time horizon (Scenario 02 in Figure 1) introduces several additional considerations into the negotiation process, including partnership quality, trust and power dynamics, and inter-party social networks. Lee and Kim established "partnership quality" as a key predictor of long-term outsourcing success by utilizing social exchange, power, and political theories (Lee and Kim, 1999). Their work focused primarily on the impacts of trust and power on partnership quality. Conceptualized as "the firm's belief that the other company will perform actions that will result in positive outcomes for the firm" (Gulati, 1995), trust considerations are germane in the context of SLA renegotiations as each party can reflect in 
hindsight upon the extent to which the other party met or failed to meet its previously-negotiated obligations. Additionally, the use of power to influence negotiation outcomes can become a relevant issue in the IT SLA renegotiation process if one party is highly-dependent upon the other in a long-term exchange relationship (Bacharach and Lawler, 1981). Finally, social network theory may also be influential in the context of iterative IT SLA renegotiations, as a contractually-mandated interorganizational relationship can facilitate the establishment and development of interpersonal working and social relationships between individuals affiliated with the parties to the negotiation. In these situations, an IT SLA may serve as a nexus through which individuals in one organization can establish working relationships and friendly ties with their counterparts in another organization -- a situation that might be termed "interorganizational homophily" (McPherson, et al., 2001). Such social networks are known to be highly influential in organizational contexts (Burkhardt, 1994), and may substantially impact the IT SLA renegotiation process insofar as the status of the long-term interorganizational relationship has direct implications for the status of the workers' interpersonal relationships, and vice-versa.

The theoretical models presented in this section may be very relevant in multiple IT SLA negotiation scenarios. These models seek to describe what occurs during the negotiation process, and may provide a starting point for the establishment of negotiation support system requirements tailored to the IT SLA domain. In the following section, we broadly describe the IT SLA negotiation process, and introduce a research model through which the applicability of several of the theories discussed above to a two-party, initial IT SLA negotiation can be evaluated.

\section{NEGOTIATION PROCESS AND RESEARCH MOD- EL}

Traditionally, negotiation has been viewed as an interaction among participants within a context of deriving mutual commitment. The construction of IT SLAs begins with initial proposals -- likely prepared in secret -- that include each party's goals and objectives. It continues with negotiation processes, and ends (successfully) when both parties agree to a specified written document. The negotiation lifecycle for IT SLAs has many similarities with the WinWin Software Requirements Negotiation Model (Egyed and Boehm, 1999). The outsourcing relationship depends largely on effective communication between participants, with exchanges of information necessary to fulfill obligations, achieve expectations and mutual satisfaction, avoid conflicts, facilitate solutions to problems and issues, reduce uncertainty, and ensure flexibility (Aiken and Hage, 1968; Easton, 1992). The negotiation lifecycle for IT SLAs differs in several important ways from software requirements negotiation, however. First, rather than simply meeting stated software requirements, IT SLAs seek to provide a high level of service quality. Second, an IT SLA is produced through interactions between at least two parties (customer and service provider), as opposed to a single party, i.e., the software development team. Finally, an IT SLA often provides a foundation for a long-term relationship rather than serving solely as a starting point for a software development project (Robinson and Volkov, 1998).

The negotiation lifecycle can be illustrated by considering the negotiation of an IT SLA between a University's Business IT group (hereafter referred to as BIT) and representatives of its current MBA students. Figure 2 illustrates such a negotiation lifecycle. In the diagram, the “Apply Win-Win spiral model...” box and the expanded and more descriptive version of this box together represent the inclusion of a particular theory-based process model, built upon such theories as those advanced above. In this way, it is possible to conceptualize the impact that a theoretical framework might have on the different aspects of the IT SLA negotiation process.

To be more specific, Figure 2 depicts a skeletal research model wherein sociological theories such as those discussed above can be mapped to IT SLA negotiation stages at phases where they are deemed most relevant. For example, the Win-Win spiral model is relevant to the stage of negotiation subsequent to agreement of a preliminary negotiation framework. A Negotiation Support System (NSS) like that developed by Boehm, et al. can utilize information derived from position artifacts containing a draft IT SLA to initiate the spiral model (Boehm and In, 1996).

By presuming the relevance of the Win-Win model, however, one is likely overlooking the research steps necessary to determine if this particular model has relevance to IT SLA negotiations. In fact, the Win-Win spiral model, while useful in negotiations involving multiple stakeholders in a requirements negotiation context, may well be irrelevant to negotiations where few win-win conditions are identifiable, the win conditions identified are highly controversial, or the win conditions are traded away as other conditions are negotiated. For this reason, it is important to step back and examine, from an exploratory perspective, those theories that might have relevance to IT SLA negotiations. The dashed lines with their "P\#" denotations in Figure 2 represent the scope of this paper's examination of the relevance of the several theories discussed above to the IT SLA negotiation process. Each $\mathrm{P}$ corresponds to a proposition that relates to theories discussed earlier. 


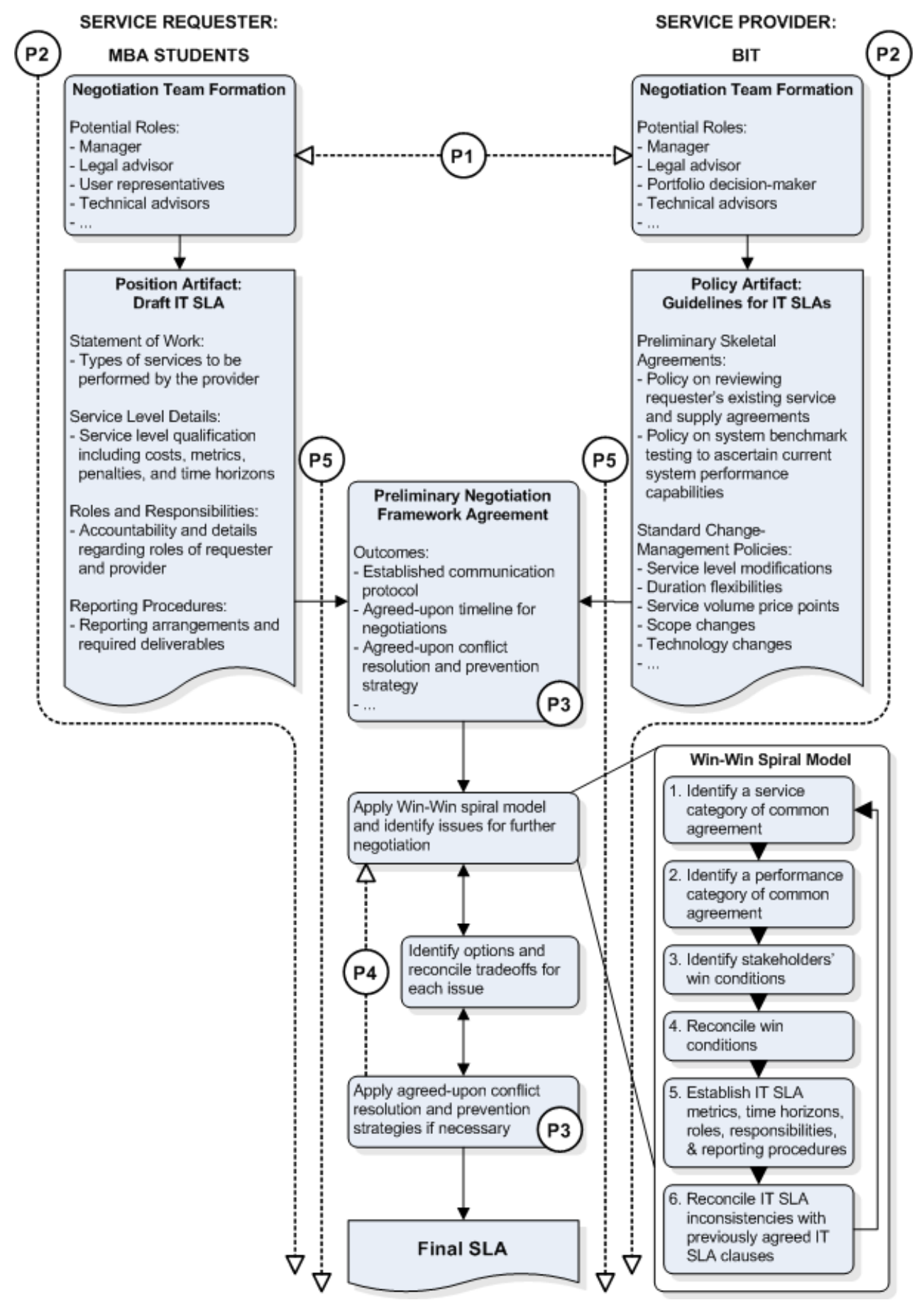

Figure 2 Sample IT SLA Negotiation Life Cycle with Theory-Driven Elements

We begin with a discussion of the knowledge gap that may exist among the IT SLA negotiation parties. Proposition 1 stipulates that the knowledge gap may have a significant impact on the success or failure of the negotiation processes and on the quality of the IT SLA produced as a result of the negotiation. This proposition is most closely associated with the formation of the teams that represent each party. Thus, we include a dashed line, labeled P1, to represent the potential point of interaction for theorydriven strategies that specifically address issues to im- prove problems that might occur in the presence of a large knowledge gap. P1 is therefore stated as follows:

Proposition 1: The degree of the knowledge gap, defined as the difference between the relevant knowledge, skills and backgrounds of the actors/parties involved in a negotiation, will have an impact on the quality of the negotiation and the outcomes generated therefrom (Köppel, et al., 1999).

Soper, D. S., Demirkan, H., \& Goul, M. (2008). Evaluating the applicability of socially-oriented perspectives to the IT service level agreement negotiation process: a theory-driven exploratory study. International Journal of Services Sciences, 1(3-4), 267-287.Copyright (c) 2008 Inderscience Enterprises Ltd. 
Along with the knowledge gap, a general classification of teams as fundamental learning and decision making units forms the basis of Bereby-Meyer, et al.'s theory (BerebyMeyer, et al., 2004), which postulates that high-learning teams outperform low-learning teams. The dashed lines in Figure 2 representing Proposition 2 therefore encompass all phases in the skeletal model. P2 is stated as follows:

Proposition 2: Teams will show improved performance as a function of their members' experience, motivation, learning processes, team discussion quality, etc. (BerebyMeyer, et al., 2004).

The next proposition we address refers to the equity theories postulated by Homans and Bartos (Bartos, 1978; Homans, 1961). Under the equity framework, fair-minded parties will seek agreements that represent midpoints of exposed differences in desired outcomes. P3 likely has relevance to two specific boxes in the skeletal model of Figure 2. First, when establishing a preliminary negotiation framework, it is reasonable to expect that this theory might aid in establishing an agreed-upon conflict resolution and prevention strategy that strives for justice and fairness. In addition, when issues rise to a stage of conflict, this theory likely has relevance to actual applications of the justice strategies agreed to earlier. P3 is thus stated as follows:

Proposition 3: A midpoint between contentious IT SLA issues will be viewed by both parties as just, and they will accept the responsibility to strive to achieve that midpoint in their negotiations (Bartos, 1978; Homans, 1961).

A fourth proposition relates to the knowledge gap issue of Proposition 1, but more clearly aligns IT SLA negotiation processes with Cross' learning theory (Cross, 1978), discussed earlier. Cross postulates that as participating teams learn about the strategies of their negotiating counterparts, they alter their own strategies to make progress toward a more optimal outcome. P4 in Figure 2 shows how this theory might apply to the IT SLA negotiation research model as the process of reaching agreements on subsets of action items is repeated or cycled through. P4 is stated as follows:

Proposition 4: During the process of negotiation, the strategy of each party will be influenced by that party's perception of the other party's strategy (Cross, 1978).

The final proposition addressed in this paper relates to the theory-driven findings of Lee and Kim (1999). Their research focused on partnership quality, a construct they found related to high-quality IT outsourcing negotiation outcomes. Partnership quality was influenced significantly by communication, participation, etc. which clearly addresses all aspects of the Figure 2 skeletal model subsequent to each party's preparation of preliminary position statements. P5 states:

Proposition 5: There is a positive relationship of the variables communication, participation, joint action, coordination, information sharing with partnership quality, and partnership quality influences negotiation outcome satisfaction (Lee and Kim, 1999).

In the following section, we describe an exploratory study designed to determine if there is reason to initiate the design of requirements for IT SLA negotiation support systems based on the above propositions and their underlying theories.

\section{EXPLORATORY STUDY METHOD AND RESULTS}

An exploratory experiment was conducted to examine the propositions discussed in the prior section. IT SLA negotiation -- and indeed using IT SLAs as research artifacts -are both quite new in a research context, and therefore require novel methodological constructs that are likely reminiscent of the nascent stages of more traditional IT research topics. In this study, we investigated an IT SLAbased sourcing relationship between a service receiver (MBA students) and a service provider (a University's Business IT group -- BIT). We focused on both parties' perceptions of the negotiation process, and we analyzed the results of pilot negotiations to address the propositions advanced above.

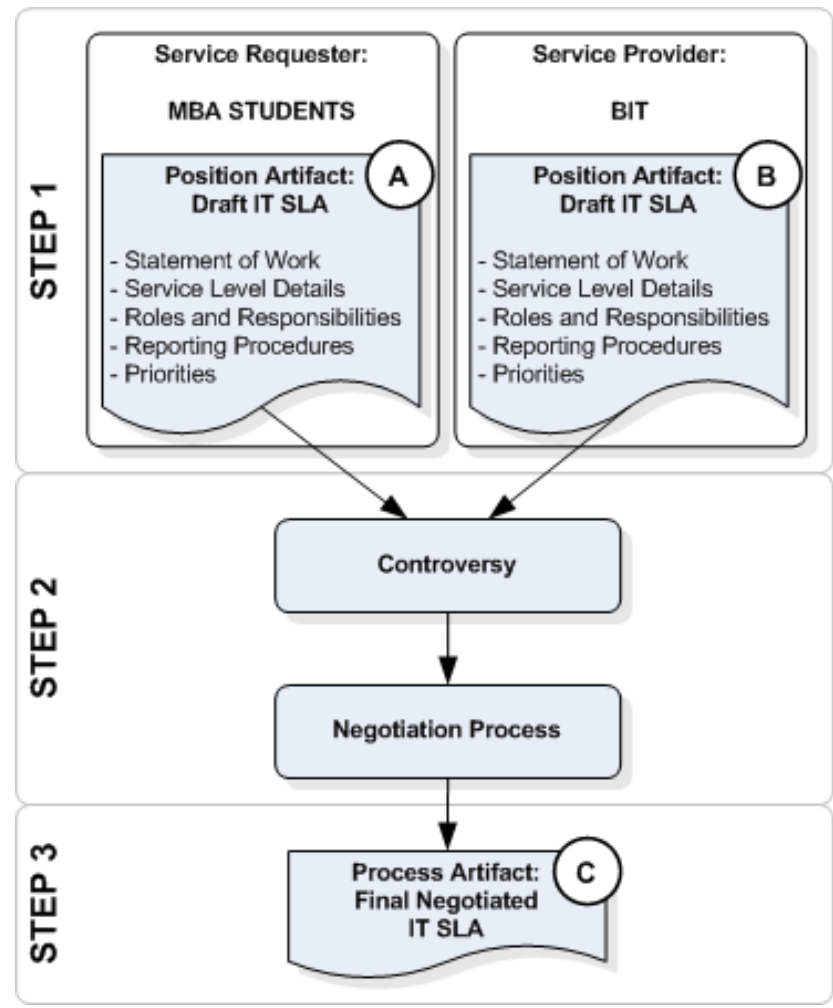

Figure 3 IT SLA Negotiation Process Model based on Sociological Theories of Negotiation and DecisionMaking

Figure 3 above shows a process model that helps in explaining the organization of the experiment. Six teams of MBA students (19 total students) participated in the study as part of the requirements of a graduate level course in the management of distributed business information sys- 
tems. All of the students reported that they had never before participated in this type of negotiation task. Each team engaged in two simultaneous negotiations with two of the other teams by playing a different role in each negotiation, i.e., in one negotiation a team was the service requester, and in the other negotiation they represented the service provider. Care was taken to ensure that any given team would only participate in the negotiation task once with any other given team. The pairing of opposing teams was also controlled for to ensure that they had not previously worked together on other projects.

The teams were instructed to prepare initial proposals (A and $B$ in Figure 3) with their needs and wants without the knowledge of the other team. Next, they conducted a twoparty negotiation, and finally, they jointly constructed a final agreed-to IT SLA document (C in Figure 3). Thus, the artifacts produced in the study included each team's initial position statement for each role (As and Bs in Figure 3) and a final IT SLA (C in Figure 3). A and B were both in the form of preliminary contracts used to focus the negotiation and to represent agreement of all group members on the terms they were striving to achieve -- all before negotiations began. C represents an agreed-to set of contractual elements specifying performance levels, measures, penalty costs, etc. The students were all taught about IT SLAs and their development using the U.S. Navy's Marine Corp Intranet contract with EDS as an exemplar (NMCI, 2005).

Each team defined their initial proposed contract artifact to cover roles and responsibilities, goals and objectives, reporting policies, help desk availabilities, penalties, incentives and adjustment procedures, etc. -- all with specific statements that addressed measurable performance levels based upon their perspective. Then, after their negotiations, the teams developed a final joint IT SLA document. Both parties were motivated to claim as much value for themselves as possible, and each party exhibited different priorities and importance levels for negotiated items. There were a total of twelve initial proposals (six each for service providers and service requesters) and six final IT SLAs.

For each of these artifacts, a data matrix was populated to capture the important areas, categories and importance levels of each item for each team (see Appendix). A matrix template was developed through an extensive review of the literature and an examination of related IT SLAs in order to develop a comprehensive set of performance areas (Y-axis) and service categories (X-axis). A performance area refers to an area where IT SLA negotiations may be required, and a service category refers to the type of service that might be relevant to that performance area. For example, the hours of operation of help desk services might be referenced in a particular contract clause in an IT SLA. This reference can be reflected in the template by the cell corresponding to the "Basic help desk services" performance area and the "availability” service category.
An example of this data matrix is provided in the Appendix.

The matrix was utilized to perform a content analysis of each initial position statement artifact relative to the final SLA artifact. The numbers in the cells of the matrix represent the relative importance level (a density count) of the occurrence of a clause in a contract artifact for the group and for the negotiation being examined. For example, the availability of desk/laptop, hardware, and operating system was included in two clauses of the contract artifact shown in the appendix. Table 1 provides an aggregated count of the "importance factors" for each performance area/service category item from the teams' initial negotiating positions. These summary data are included in order to provide a synopsis of the nature of the data collected.

In addition to the review of the aggregated count of "importance factors", we performed a comparative overlap analysis to assess the degree of similarity between opposing teams' initial proposals, and between those initial proposals and the final negotiated IT SLA. These similarity values are reported in Table 2 below.

A larger number in the table represents the closeness of the artifact overlap. For example, in Negotiation 1 the initial proposals' overlap with each other was 32 points, while the BIT team's initial proposal overlap with the final IT SLA was 90 points as opposed to 32 points for the MBA team. Thus, almost all of BIT's, and some of the MBA students' requirements were included in the final negotiated IT SLA.

The teams in this pilot study were comprised of students with similar backgrounds who played identical roles in the two assigned negotiation tasks, i.e., each team acted as both a service requester and as a service provider. As such, we assume that the knowledge gap between teams was kept to a minimum. This assumption enables us to reach stronger conclusions regarding the other propositions where variations could have been attributed to a large knowledge gap. We do, however, believe that the knowledge gap proposition is a significant one, and that it is necessary to incorporate decision aids intended to close identified knowledge gaps in NSS requirements. This reconciliation of knowledge is particularly applicable to gaps associated with explaining the business processes that are to be addressed in the IT solution.

For virtually all of the negotiations, the opponents' initial proposals were significantly different. However, some of the proposals tended to subsume other proposals, thereby indicating differences in the approach taken to negotiation preparation between teams or a knowledge gap between teams. It may also be the case that some teams were simply higher performers than others. For example, the aggregate importance count of every scored aspect for BIT in Table 1 is 380, while the MBA Students' aggregate count is 481. It can therefore be said that the MBA students addressed nearly $26 \%$ more items in their proposals than BIT groups. We use similar generalizations in the follow- 
ing to make preliminary statements about the propositions discussed earlier in the paper.

By examining the initial proposals and the final agreement documents, we noticed evidence supporting the validity of Proposition 2. Teams who were well prepared and motivated in the early phase and throughout the negotiation process achieved a much higher level of performance in the end. Specifically, as opposed to teams that were less prepared and less motivated, these teams were able to ensure that many more of the items identified in their initial proposals were ultimately included as part of the final negotiated IT SLA. This finding provides support for the postulation that team learning and motivation plays a significant role in a team's success in the IT SLA negotiation process.

Evidence also surfaced in this study that disagrees with the "justice" model advanced by Proposition 3. The overlap analysis comparing teams' initial proposals to the final negotiated IT SLA clearly showed that the negotiations did not result in an equitable midpoint that balanced considerations from both teams' initial proposals. Predominant winners and losers were evident for each negotiation. ticipants in the study were MBA students with similar professional and academic backgrounds. From post-hoc informal discussions held with the participants regarding the results of the final IT SLAs, we discovered that the teams all employed a different strategy, each of which was based upon the team's perception of their opponent's strategy. This finding provides incidental evidence of the validity of Proposition 4, although our methodological constructs do not presently provide clear quantitative support of this finding.

To analyze Proposition 5 and the impacts of individual's behavior on the experimental outcomes, we developed several surveys and distributed them to all of the participants in the study. A content analysis of these surveys revealed trends in the data indicating that participants who were complacent regarding their IT usage were often poorer contributors to initial position artifacts, regardless of whether the team was playing the provider role or the requester role at the time. We have also observed that prefactual thinkers, or pessimists, tend to contribute more significantly during the negotiation process than do their optimistic counterparts.

As mentioned previously, we controlled environmental factors in this study as closely as possible. All of the par-

Table 1 Aggregate Summary of Initial IT SLA Proposals

\begin{tabular}{|r|c|c|c|c|}
\hline \multirow{2}{*}{ PRE-NEGOTIATION AGGREGATE BIT IMPORTANCE FACTORS } \\
\hline \multirow{2}{*}{ Service Area } & \multicolumn{4}{c|}{ Performance Area } \\
\cline { 2 - 5 } & Manageability & Usability & Consistency & Resolvability \\
\hline User Services & 26 & 123 & 62 & 23 \\
\hline Maintenance and Help Desk Services & 8 & 28 & 6 & 19 \\
\hline Communication and System Services & 3 & 20 & 10 & 4 \\
\hline Information Assurance Services & 2 & 10 & 6 & 2 \\
\hline Other Requirements & 2 & 15 & 8 & 3 \\
\hline PRE-NEGOTIATION AGGREGATE MBA STUDENT IMPORTANCE FACTORS & Resolvability \\
\hline \multirow{2}{*}{ Service Area } & \multicolumn{5}{|c|}{ Performance Area } \\
\cline { 2 - 5 } & Manageability & Usability & Consistency & 28 \\
\hline User Services & 51 & 138 & 74 & 23 \\
\hline Maintenance and Help Desk Services & 7 & 37 & 8 & 3 \\
\hline Communication and System Services & 7 & 25 & 17 & 2 \\
\hline Information Assurance Services & 2 & 11 & 7 & 5 \\
\hline Other Requirements & 2 & 19 & 15 & \\
\hline
\end{tabular}

Table 2. Artifact Overlap Analysis

\begin{tabular}{|r|r|r|r|r|r|r|}
\hline $\begin{array}{c}\text { Negotiation } \\
\text { ID }\end{array}$ & $\begin{array}{c}\text { BIT } \\
\text { Team } \\
\text { ID }\end{array}$ & $\begin{array}{c}\text { MBA } \\
\text { Team } \\
\text { ID }\end{array}$ & $\begin{array}{c}\text { Overlap - } \\
\text { Initial Pro- } \\
\text { posals }\end{array}$ & $\begin{array}{c}\text { Overlap - BIT } \\
\text { Initial Pro- } \\
\text { posal \& Final } \\
\text { IT SLA }\end{array}$ & $\begin{array}{c}\text { Overlap - MBA } \\
\text { Initial Pro- } \\
\text { posal \& Final } \\
\text { IT SLA }\end{array}$ & $\begin{array}{c}\text { Average Overlap - } \\
\text { Cumulative Total of } \\
\text { Initial Proposals } \\
\text { and Final IT SLA }\end{array}$ \\
\hline 1 & 2 & 5 & 32 & 90 & 32 & 89 \\
\hline 2 & 1 & 6 & 28 & 30 & 78 & 86 \\
\hline 3 & 3 & 4 & 43 & 39 & 108 & 74 \\
\hline 4 & 4 & 1 & 24 & 18 & 76 & 708 \\
\hline
\end{tabular}




\begin{tabular}{|r|r|r|r|r|r|r|}
\hline 5 & 5 & 3 & 28 & 28 & 184 & 184 \\
\hline 6 & 6 & 2 & 36 & 32 & 30 & 50 \\
\hline
\end{tabular}

\section{CONCLUDING REMARKS}

The research reported herein represents one of the first attempts to understand the role played by social factors in IT SLA negotiations; it is believed that an understanding of these factors can usefully inform design requirements for negotiation support systems (NSS) that are specifically tailored to the IT SLA negotiation context. The current paper focused on two-party initial IT SLA negotiations (Scenario 01 in Figure 1); future work should endeavor to evaluate the extent to which our findings can be generalized to the more complex negotiation scenarios. A number of preliminary insights were identified in this study: First, motivation and learning were found to have a significant impact on negotiator performance. Second, and perhaps most important, teams that were well-prepared for the negotiation process were found to outperform their less prepared counterparts with respect to the nature of the final negotiated IT SLA document. This finding indicates the importance of incorporating significant up-front guidance regarding the construction of IT SLAs into NSSs that are designed to support the IT SLA negotiation process. Furthermore, the results reported herein seem to indicate that this stream of research can be expanded from its current nascent stage -- which is characterized by the development and evaluation of theorydriven propositions -- to include stronger methodologies leading to testable hypotheses and theory development. Emerging methodologies such as those proposed by Soper et al. may be useful in that regard (Soper, et al., 2005).

Our findings also call into doubt the relevance of equitybased social justice theories to the IT SLA negotiation process. It may be that a predisposition towards self-interest among the members of a negotiation team results in a negotiation environment that is characterized more by positional bargaining than by principled negotiation. In such a scenario, individual predispositions may have an impact on team performance, and by extension, on the nature and quality of the final IT SLA itself. To that end, both an individual perspective and a group perspective will likely be required in order to fully understand the IT SLA negotiation process. In conjunction with Scenarios 02, 03, and 04 from Figure 1, this implies several rich possibilities for further studies in this area that examine the potential roles of game theory, political theories, and economic theories to the IT SLA negotiation process. The examination of these theories, however, will likely require new evaluative constructs such as the data matrices and distance/similarity coefficient approaches utilized herein in order to coalesce a comprehensive IT SLA and all of its specifics into viable hypothesistesting metrics. That having been said, both the complexity of the IT SLA artifacts and the growing importance of IT SLA negotiations to a globalized business world indicate that we are only at the beginning of a significant field of study for negotiation support systems suited to this purpose.

\section{ACKNOWLEDGMENTS}

The authors acknowledge helpful discussions related to three reviewers for the Hawaii International Conference and another three reviewers for the International Journal of Services Science provided invaluable anonymous input to give us leverage to improve the quality of this research.

\section{REFERENCES}

Aiken, M., and Hage, J. "Organizational Interdependence and Intra-Organizational Structure," American Sociological Review (33:6), 1968, pp. 912-930.

Bacharach, S.B., and Lawler, E.J. Power and Politics in Organizations: The Social Psychology of Conflict, Coalitions, and Bargaining, Jossey-Bass, San Francisco, CA, 1981.

Bartos, O.J. "Simple Model of Negotiation: A Sociological Point of View," In The Negotiation Process: Theories and Applications, I. W. Zartman (ed.) Sage Publications, Beverly Hills, CA, 1978.

Bereby-Meyer, Y., Moran, S., and Unger-Aviram, E. "When performance goals deter performance: Transfer of skills integrative negotiations," Organizational Behavior and Human Decision Process (93), 2004, pp. 142-154.

Boehm, B., and In, H. "Identifying quality-requirement conflicts," Software, IEEE (13:2), 1996, pp. 25-35.

Braunstein, A. Working Effectively with Standard Outsourcing Contracts, Robert Francis Group, Inc., Westport, CT, 2004.

Burkhardt, M.E. "Social interaction effects following a technological change: a longitudinal investigation," Academy of Management Journal (37), 1994, pp. 869-898.

Cross, J.G. "Negotiation as a learning process," In The Negotiation Process: Theories and Applications, I. W. Zartman (ed.) Sage Publications, Beverly Hills, CA, 1978.

Easton, G. "Industrial Networks: A Review," In Industrial Networks: A New View of Reality, B. Axelson and G. Easton (eds.), Routledge, London, UK, 1992.

Egyed, A., and Boehm, B. "Comparing Software System Requirements Negotiation Patterns," Systems Engineering Journal (6:1), 1999, pp. 1-14.

Gartner IT Outsourcing Market Forecast: Worldwide, 2002-2007, Gartner, Inc., Stamford, CT, 2004.

Gulati, R. "Does familiarity breed trust? The implications of repeated ties for contractual choice in alliances," Academy of Management Journal (38:1), 1995, pp. 85-112.

Homans, G.C. Social Behavior -- Its Elementary Forms, Harcourt Brace Jovanovich, New York, NY, 1961. 
Humphrey, W.S. Managing the Software Process, AddisonWesley, Boston, MA, 1989.

Karten, N. How to establish Service Level Agreements, Randolph, MA, Karten Associates, 1998

Kern, T. "The Gestalt of an information technology outsourcing relationship: an exploratory analysis," Proceedings of the Eighteenth International Conference on Information Systems (ICIS), Atlanta, GA, 1997.

Köppel, A., Böning, D., and Abeck, S. "How to Support the Negotiation of Service Level Agreements (SLAs) for Your Client/Server Application," Proceedings of the Third World Multiconference on Systemics, Cybernetics and Informatics (SCI) and the Fifth International Conference on Information Systems Analysis and Synthesis (ISAS), Orlando, FL, 1999.

Lee, J.-N., and Kim, Y.G. "Effect of Partnership Quality on IS Outsourcing Success: Conceptual Framework and Empirical Validation," Journal of Management Information Systems (15:4), 1999, pp. 29-61.

Lim, L.H., and Benbasat, I. "A theoretical perspective of negotiation support systems," Journal of Management Information Systems (9:3), 1992-1993, pp. 27-45.

McPherson, M., Smith-Lovin, L., and Cook, J. "Birds of a feather: Homophily in Social Networks," Annual Review of Sociology (27), 2001, pp. 415-444.

NextSLM Service Level Management -- North America Survey 2000, BMC Software, Houston, TX, 2000.

NMCI U.S. Navy Marine Corp Intranet SLA Contract, U.S. Navy Marine Corp Intranet, Arlington, VA, 2005.

Norem, K.J., and Cantor, N. "Anticipatory and Post Hoc Cushioning Strategies: Optimism and Defensive Pessimism in "Risky"
Situations," Cognitive Therapy and Rresearch (10:3), 1986, pp. 347-362.

Polzer, J.T., Mannix, E.A., and Neale, M.A. "Interest Alignment and Coalitions in Multiparty Negotiation," The Academy of Management Journal (41:1), 1998, pp. 42-54.

Prinzel III, L.J., DeVries, H., Freeman, F.G., and Mikulka, P. Examination of Automation-Induced Complacency and Individual Difference Variates, Langley Research Center, Hampton VA, 2001.

Rahwan, I., Sonenberg, L., and Dignum, F. "Towards InterestBased Negotiation," Proceedings of the Second International Joint Conference on Autonomous Agents and Multiagent Systems, Melbourne, Australia, 2003.

Robinson, W.N., and Volkov, S. "Supporting the Negotiation LifeCycle," Communications of the ACM (41:5), 1998, pp. 95-102.

Sanna, L.J. "Defensive Pessimism, Optimism, and Simulating Alternatives: Some Ups and Downs of Prefactual and Counterfactual Thinking," Journal of Personality and Social Psychology (71:5), 1996, pp. 1020-1036.

SEI The Capability Maturity Model: Guidelines for Improving the Software Process, Addison-Wesley, Boston, MA, 1995.

Soper, D.S., Goul, M., Demirkan, H., Aranda, E., and Aranda, L. "A Vector-Based, Content-Analytic Methodology for Comparing Negotiated IT Service Level Agreements," Proceedings of the Eleventh Americas Conference on Information Systems (AMCIS), Omaha, NE, 2005.

Ury, W., Fisher, R., and Patton, B. Getting to Yes: Negotiating Agreement Without Giving In, Penguin Books, New York, NY,

1991. 


\section{APPENDIX - SAMPLE DATA MATRIX}

\begin{tabular}{|c|c|c|c|c|c|c|c|c|c|c|c|c|c|c|c|c|c|c|c|}
\hline & 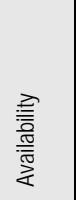 & 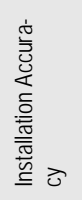 & 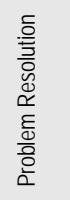 & 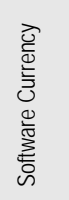 & 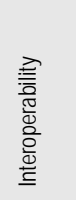 & 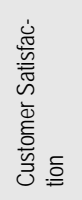 & 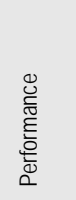 & 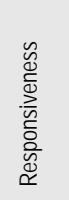 & 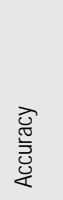 & $\begin{array}{l}\text { 言 } \\
\text { 兽 }\end{array}$ & 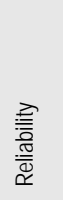 & 胥 & 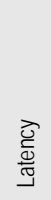 & 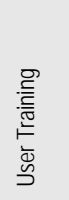 & 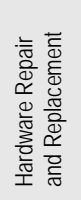 & 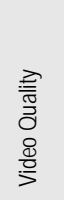 & 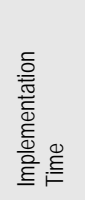 & 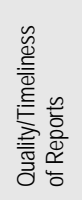 & 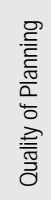 \\
\hline \multicolumn{20}{|l|}{ User Systems } \\
\hline $\begin{array}{l}\text { Deskllaptop hardware } \\
\text { and operating sys. }\end{array}$ & 2 & & & & 3 & & 1 & & & & 1 & & & & & & & & \\
\hline \multicolumn{20}{|l|}{ End User Services } \\
\hline $\begin{array}{l}\text { Standard office auto- } \\
\text { mation software }\end{array}$ & & 1 & & 1 & & & & & 2 & & 1 & & & & & & & & \\
\hline E-mail services & 1 & & & & & & & & & & & 1 & & 1 & & & 1 & & \\
\hline \multicolumn{20}{|l|}{ Directory services } \\
\hline $\begin{array}{l}\text { File shared ser- } \\
\text { vices/storage }\end{array}$ & 2 & & & & & & & & 1 & & & 1 & & 1 & & & & & \\
\hline \multicolumn{20}{|l|}{ Web access services } \\
\hline \multicolumn{20}{|l|}{ Newsgroup services } \\
\hline $\begin{array}{l}\text { Multimedia capabilities } \\
\text { services }\end{array}$ & & & 2 & & 2 & & & & & & & & & & & & & & \\
\hline Print services & 2 & & & & & & 1 & & & & 1 & & & 1 & & & & & \\
\hline $\begin{array}{l}\text { Intranet perf./capa. } \\
\text { (CMC, Room res.,etc.) }\end{array}$ & 2 & & & & & & & 2 & & & & & & 1 & & & & & \\
\hline Internet access & 1 & & & & & & & & & & & & & & & & & & \\
\hline $\begin{array}{l}\text { University computing } \\
\text { system access }\end{array}$ & & & 3 & & & 2 & & & & & & & & 1 & & & & & \\
\hline $\begin{array}{l}\text { Access to School } \\
\text { software }\end{array}$ & & & & & & & & & & 2 & & & & & & & & & \\
\hline $\begin{array}{l}\text { Moves, adds and } \\
\text { changes }\end{array}$ & & & & & & & & 2 & & & & & & & & & & & \\
\hline $\begin{array}{l}\text { Software distribution } \\
\text { and upgrades }\end{array}$ & 1 & 1 & & & & & & & & & & & & & & & & & \\
\hline User training & 1 & & & 1 & & & & & & & & & & & & & & & \\
\hline Remote access & 1 & & & & & & & 2 & & & & & & 1 & & & & & \\
\hline Wireless access & 1 & & & & & & 1 & & & & 1 & 1 & & & & & & & \\
\hline $\begin{array}{l}\text { Class/Teamroom/Lab } \\
\text { (general,fax,staplis..) }\end{array}$ & 5 & & & & & 1 & & & & 2 & 1 & & & 1 & & & 1 & & \\
\hline \multicolumn{20}{|l|}{$\begin{array}{l}\text { Maintenance and help } \\
\text { desk services }\end{array}$} \\
\hline $\begin{array}{l}\text { Basic help desk } \\
\text { services }\end{array}$ & 1 & & 1 & & 1 & & & 1 & & & & & & 1 & & & & & \\
\hline $\begin{array}{l}\text { Computer (Laptop) } \\
\text { Repairs }\end{array}$ & & & & & & & & 1 & & & 1 & & & & 1 & & & & \\
\hline Communication & & & & & & & & & & & & & & & & & & & \\
\hline
\end{tabular}

Soper, D. S., Demirkan, H., \& Goul, M. (2008). Evaluating the applicability of socially-oriented perspectives to the IT service level agreement negotiation process: a theorydriven exploratory study. International Journal of Services Sciences, 1(3-4), 267-287.Copyright (C 2008 Inderscience Enterprises Ltd. 


\begin{tabular}{|c|c|c|c|c|c|c|c|c|c|c|c|c|c|c|c|c|c|c|c|}
\hline & 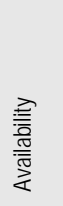 & 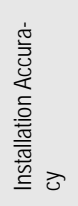 & 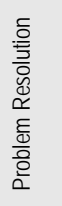 & 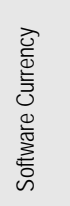 & 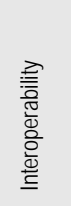 & 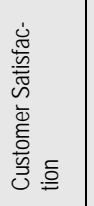 & 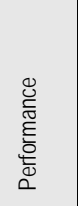 & 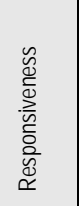 & $\begin{array}{l}\text { 产 } \\
\text { 产 }\end{array}$ & 言 & 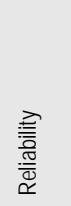 & 莺 & $\begin{array}{l}\text { 產 } \\
\text { 产 }\end{array}$ & 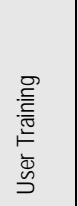 & 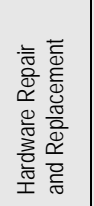 & 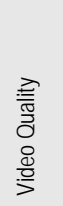 & 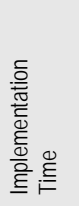 & 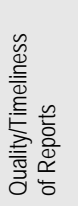 & 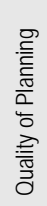 \\
\hline \multicolumn{20}{|l|}{ services } \\
\hline $\begin{array}{l}\text { Wide area network } \\
\text { connectivity }\end{array}$ & & & & & & & & 2 & & & & & & & & & & & \\
\hline $\begin{array}{l}\text { LAN communications } \\
\text { services }\end{array}$ & 1 & & 1 & & & & & & & 1 & & & & & & & & & \\
\hline $\begin{array}{l}\text { Proxy y and caching } \\
\text { services }\end{array}$ & & & & & & 1 & & & & & & & & & & & & & \\
\hline \multicolumn{20}{|l|}{ External networks } \\
\hline $\begin{array}{l}\text { Systems Services } \\
\text { Network management }\end{array}$ & 1 & & & 2 & & & & & & & 3 & & & & & & & & \\
\hline $\begin{array}{l}\text { systems services } \\
\text { Operational support }\end{array}$ & & 2 & & & & & 2 & & 1 & & & & & & & & & & \\
\hline $\begin{array}{l}\text { services } \\
\text { Canatingning }\end{array}$ & & & & & & & & & & & & & & & & & & & \\
\hline \multirow{2}{*}{\multicolumn{20}{|c|}{$\begin{array}{l}\text { Capacily planning } \\
\text { Domain name server } \\
\text { performance }\end{array}$}} \\
\hline & & & & & & & & & & & & & & & & & & & \\
\hline $\begin{array}{l}\text { Applinatitin server } \\
\text { connectivity }\end{array}$ & & & & & 1 & & & & & & 1 & & & & & & & & \\
\hline $\begin{array}{l}\text { Network operations } \\
\text { end-user communica- } \\
\text { tion }\end{array}$ & 2 & & & & & 1 & 2 & & & 2 & & & & & & & & & \\
\hline \multicolumn{20}{|l|}{ Network Maintenance } \\
\hline $\begin{array}{l}\text { Information Assurance } \\
\text { Services }\end{array}$ & & & & & & 2 & & & & & & 1 & & & & & & & \\
\hline $\begin{array}{l}\text { General security } \\
\text { provisions }\end{array}$ & & & 1 & & & & & & 1 & & & & & 1 & & & & & \\
\hline \multicolumn{20}{|l|}{ Security planning } \\
\hline 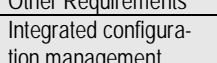 & & 2 & & 1 & & & 1 & & & & 1 & & & & & & & & \\
\hline \multicolumn{20}{|l|}{ Integration and testing } \\
\hline $\begin{array}{l}\text { Technology refresh- } \\
\text { ment }\end{array}$ & 2 & & & & & & & & & 2 & & & & & & & & & \\
\hline \multicolumn{20}{|l|}{ Technology insertion } \\
\hline $\begin{array}{l}\text { Prof \& Student Re- } \\
\text { sponsibility }\end{array}$ & & & & & & 1 & & & & & 1 & & & & & & & & \\
\hline Course Information & & & & & & & & & 1 & & & & & & & & & & \\
\hline
\end{tabular}

